This is a postprint version of:

Morillo, F. (2019). Collaboration and impact of research in different disciplines with international funding (from the EU and other foreign sources). Scientometrics, 120(2), 807-823.

\title{
Collaboration and impact of research in different disciplines with international funding (from the EU and other foreign sources)
}

Fernanda Morillo (1)

(1) IFS, Spanish National Research Council (CSIC), Albasanz, 26-28, 28037 Madrid, Spain.

E-mail address: fernanda.morillo@cchs.csic.es

\section{Abstract}

The advancement of scientific research requires an adequate investment, which calls for promoting fair political decisions about the allocation of limited resources. In this context, funders need to be properly informed to assess the results of research lines or programmes. The WoS databases can help in making decisions, since they include the funding acknowledgements of documents along with additional useful data. The purpose of this paper is to analyse, in four different disciplines, the possible relation between international funding (from the EU and other foreign sources) and collaboration and impact. WoS articles with a Spanish address and written in English are selected (period 2010-2014), classifying them according to the existence or absence of funding acknowledgements, and identifying international sponsorship and the presence of EU funds. After applying some logistic regression models, the results confirm the hypotheses, except for some unexpected findings. In general, articles with international funding present greater collaboration, especially international and larger for those supported by only other non-EU foreign funds, with some differences between disciplines. This internationally funded research also achieves the highest citation rates, being unexpectedly higher for publications sponsored by EU funds, even showing less cooperation than those supported by other foreign funds. In the same way, the proportion of articles with only national funding is not diminished by their limited percentage of collaboration. In conclusion, this paper provides interesting information, both for funders and researchers, discussing the various characteristics and disparities between disciplines and funding sources.

\section{Keywords}

WoS; Funding acknowledgements; Research fields; International funding sources; Collaboration; Impact

\section{Introduction}

The research advancement requires an adequate investment to face the different challenges existing in the daily work of scientists (Ebadi and Schiffauerova 2015; Wu et al. 2018). Policymakers devote significant efforts to the promotion of scientific research, making decisions about the allocation of limited resources that affect the size and efficiency of the R\&D system as a whole. Moreover, when it comes to establishing research priorities, these decisions are increasingly 
This is a postprint version of:

Morillo, F. (2019). Collaboration and impact of research in different disciplines with international funding (from the EU and other foreign sources). Scientometrics, 120(2), 807-823.

The final publication is available at Springer via

influenced by the commitment to link them with social needs (MacLean et al. 1998a). For this reason, it is essential to properly evaluate government policies and the performance of researchers who have obtained support (Wang and Shapira 2015). Evaluation is not only important for policymakers to decide on future strategies, but also for individual researchers to be able to identify hot topics and sources of funding. In spite of this, there is scant evidence on the effectiveness of these policies, perhaps because most of the results are achieved in the long term, which makes them particularly difficult to measure and attribute to certain research lines or programmes (Jaffe 2002; Langfeldt et al. 2015; Rigby 2011).

In this sense, the study of funding recognitions through the WoS databases offers a broader and more adequate context to obtain pertinent and accurate information useful for both policymakers and scientific researchers. The initiatives from funding agencies, collecting data on the research they finance are insufficient because they exclude the interactions that occur with other sources of funding. WoS includes information on funding acknowledgements since 2008 (for the SCI-E database), which provides a reference framework for the different funders. On the one hand, they present a context of each scientific discipline, while allowing international comparisons. On the other hand, they collect additional data from publications, such as sponsorships from other funding sources or the impact of research, and make possible the relationship between available resources and the results obtained (Gök et al. 2016; Grassano et al. 2017; Morillo and Álvarez-Bornstein 2018; Wang and Shapira 2011).

Previous works have analysed funding comparing various research fields. For instance, some authors study the presence of funding acknowledgements in each field (Álvarez-Bornstein et al. 2018; Costas and van Leeuwen 2012; Díaz-Faes and Bordons 2014; Huang and Huang 2018), while others examine the research impact in relation to the subject of study, finding higher figures in medical areas with joint public-private funds (Morillo 2016). For their part, Huang and Huang (2018) recommend that government agencies improve their understanding of the real needs of some less-funded thematic fields such as the humanities. In this sense, to delve into the knowledge of the characteristics of different disciplines with respect to international funding, this document analyses both collaboration and impact.

In relation to the cooperative aspect of research, it has always been considered beneficial for both researchers and society, because it allows combining resources, skills and ideas, and the development of new knowledge, improving the flow of information and the possibility of accessing new funding support. Collaboration between disciplines and distant organisations is now possible thanks to communication technologies, which allows us to face joint challenges, although it also entails some costs (Cummings and Kiesler 2005). Nonetheless, authors such as Nomaler et al. (2013) estimate that the international collaboration between geographically distant partners enables to increase the dissemination of the performed research and therefore its impact. The present work uses the most common way of measuring collaboration in bibliometric studies, that is, through coauthorship. Nevertheless, this procedure is not free of criticism; authors such as Laudel (2002) point out that bibliometric indicators based on coauthorship are not capable of detecting about half of the scientific cooperation that actually takes place. In line with this, Clark and Llorens (2012) 
This is a postprint version of:

Morillo, F. (2019). Collaboration and impact of research in different disciplines with international funding (from the EU and other foreign sources). Scientometrics, 120(2), 807-823.

The final publication is available at Springer via

analyse survey data to quantify it, and observe a positive relationship between federal funding and collaboration, albeit with certain limits. For their part, Ebadi and Schiffauerova (2015) study the ability to obtain financial support considering various factors such as past productivity, age or scientific collaboration. These authors conclude that, although past productivity influences the amount of funding received, belonging to large research teams and being able to connect with productive researchers increases the possibilities of obtaining financial support. Notwithstanding, the relationship between funding and collaboration with respect to impact has not yet been sufficiently explored, especially in its international aspect.

With regard to impact, several authors have indicated that the research that acknowledges funding support has more citations than the one that does not mention any financial support (e.g. Ebadi and Schiffauerova 2016; MacLean et al. 1998b; Wang and Shapira 2015). Furthermore, this research presents higher collaboration and international collaboration rates, which may also influence the increase in impact (see for example Álvarez-Bornstein et al. 2018; Yan et al. 2018; Zhao 2010). However, Mongeon et al. (2016) observe that, although financing is strongly linked to productivity and impact, an increase of it does not imply a proportional increase of the other variables. These authors, as well as others like Clark and Llorens (2012), believe that the coordination of large projects and/or the writing of new proposals can diminish the capabilities of researchers to pursue intellectual achievements. On the other hand, although funding generally improves citations, there are differences between disciplines that may be due both to their own characteristics and to the different types of support obtained, which may have various effects on the impact (Yan et al. 2018). For this reason, this work examines four different disciplines, with the aim of analysing their features and relating them to the collaborative habits of their researchers, their ability to obtain funds, their international orientation and the impact of their works.

\section{Objectives}

The objective of this paper is to study the presence and effect of international funding in four research fields with different characteristics. Particularly, the EU and only other foreign sources are analysed to evaluate their possible links with collaboration and impact. Taking all this into account, several hypotheses are considered:

1. It is expected that there will be a greater proportion of international funding acknowledgements in research fields with a clear international orientation.

2. Moreover, greater inter-institutional cooperation in articles with some international support is assumed, regardless of discipline. This collaboration will be mainly international in nature and proportionally larger for research funded by only other non-EU foreign sources.

3. Finally, it is expected that internationally funded research will have the greatest impact, although without significant differences according to the origin of the funds (the EU versus others). 
This is a postprint version of:

Morillo, F. (2019). Collaboration and impact of research in different disciplines with international funding (from the EU and other foreign sources). Scientometrics, 120(2), 807-823.

The final publication is available at Springer via https://doi.org/10.1007/s11192-019-03150-8

\section{Materials and methodology}

WoS articles from 2010-2014 are analysed and those with a Spanish address and written in English are selected, because only these include funding acknowledgements (FA). In addition, four SCI-E research fields belonging to two different areas are chosen. On the one hand, a pair of disciplines are studied from the area of Life Sciences: Agriculture, Dairy \& Animal Science (Agric) and Biodiversity Conservation (Biodiv). The first comprises a more applied and domestic research, while the second is more basic and international. On the other hand, two topics are analysed from the area of Technology: Spectroscopy (Spectro) and Telecommunications (Telecom). In this case, the first is more basic than the second and with greater international collaboration. Some indicators are obtained for each of the articles of these four disciplines: number of authors, organisations and countries, and the relative citation rate to the world average $(R C R)^{1}$. Furthermore, items are examined to verify the existence or absence of cooperation among organisations, identifying whether collaboration is international. Besides, articles from each discipline are classified according to the existence or absence of FA, determining whether funding sources are national (including ESIF $^{2}$ ) or international, and detecting the presence or absence of EU funds.

Bearing in mind the numerous difficulties in handling the WoS funding data, as several authors have noted (e.g. Álvarez-Bornstein et al. 2017; Wang and Shapira 2011), the present study has taken advantage of the automation processes previously developed (see Morillo and Álvarez-Bornstein 2018). These automation processes analyse the documents with data in the FA field, extracting and identifying the main funding agencies. The shortest sponsors' variants are selected so that they can serve as keywords in the automatic location of the publications funded by these sponsors. Moreover, their place of origin is assigned in a standardised manner, whenever possible, to select only those records that match with each other. Although standardisation implies a manual verification, some of the tasks are performed automatically, taking advantage of the acronyms and grouping variants with a high level of similarity. All these automatic processes allow locating specific funders, although in this work only their geographical location is used, distinguishing between articles supported by national sources (in this case, Spanish) and articles supported by international sources (non-Spanish). For example, a document is allocated in the set with only national FA when it has the exclusive support of the Spanish Ministry of Economy and Competitiveness, while it is allocated in the set with international FA when it only has the support of the USA National Foundation of Science. In addition, it is also allocated as international FA if the document receives funds from both sources. Likewise, the international FA set is analysed to identify EU agencies and programmes, which are allocated in the EU FA set (e.g. the European Union's Horizon research and innovation program).

\footnotetext{
${ }^{1}$ To allow comparisons between disciplines, the RCR is calculated as the count of citations received by a document in a given discipline and year with respect to the world average number of citations in the same discipline and year.

${ }^{2}$ European Structural \& Investment Funds (ESIF) consist of five funds including European Regional Development Fund (ERDF) and European Social Fund (ESF). The EU countries administer the funds on a decentralised basis through shared management (extracted from https://ec.europa.eu/eip/ageing/funding/ESIF en).
} 
This is a postprint version of:

Morillo, F. (2019). Collaboration and impact of research in different disciplines with international funding (from the EU and other foreign sources). Scientometrics, 120(2), 807-823.

The final publication is available at Springer via

Furthermore, several logistic regression models are applied to the whole data set to determine which factors affect the presence/absence of international funds (dependent variable). Likewise, within those with international support, similar models are applied to determine which factors affect the presence/absence of EU funds (dependent variable). The disciplines to which these publications belong have also been considered. The independent variables selected include the $R C R$, the number of authors (continuous variables, Table 2), the presence of international collaboration and the four disciplines (nominal variables, Table 1). Disciplines are introduced as dummy variables, indicating in the results which is the reference category (Agric). To avoid multicollinearity problems, other types of collaboration and the number of organisations and countries are excluded. Logistic regression models are built with all the variables of interest, obtaining both the main effects and the interactions between them. Additionally, to determine the goodness of fit of the models, the Nagelkerke's pseudo- $R^{2}$ statistic is employed and the number of correctly classified cases with respect to the null model. Finally, the Wald's test is used to calculate the statistical significance of the parameters of the models, setting a p-value less than 0.05 .

\section{Results}

\section{General Data}

At a first glance, the average financial support is very high (80\%), with a low percentage of articles without FA in the disciplines analysed, varying from $13 \%$ in Biodiv to $26 \%$ in Agric. If papers with FA are examined, it is possible to distinguish those with only national funds from those that include international funding. The total number of articles analysed accounts for 6,835 , excluding the small proportion of items of unknown origin (less than 1\%). As seen in Table 1 , Agric has a remarkable weight of only national FA (49\%), while Biodiv is the discipline with the highest international orientation of its funds ( $47 \%$ ). The latter is the only one representing more than $50 \%$ of the total FA, contrary to what happens with the average, being only national FA the one that stands out. If the international FA set is analysed, it is possible to differentiate articles with only other foreign FA from those that include the EU FA. In all disciplines, except Telecom (65\%), the weight of EU funds is the lowest, especially in Agric, which is the discipline with the highest percentage of funding from only other foreign origin (73\%).

With regard to collaboration between organisations (Table 1), the average percentage for all disciplines is high $(73 \%)$, but there are important variations that range from $16 \%$ without collaboration in Biodiv to almost $36 \%$ in Telecom. Concerning the distribution of the collaboration, there are also relevant differences, being Agric the one that stands out for its only national orientation (36\%), Biodiv for its weight in international cooperation (almost 60\%), and Telecom for its low percentage of only national collaboration (less than 20\%). In addition, in the set with only national FA, Telecom is also the discipline with the lowest percentage of collaborative articles (less than $50 \%)$. Nevertheless, cooperation in this set is on average very low (61\%), even lower than that without FA. Conversely, the set with international FA is the one with the highest collaboration proportion (88\%), especially of international type (Appendix Table 5 ). Finally, if continuous 
This is a postprint version of:

Morillo, F. (2019). Collaboration and impact of research in different disciplines with international funding (from the EU and other foreign sources). Scientometrics, 120(2), 807-823.

The final publication is available at Springer via https://doi.org/10.1007/s11192-019-03150-8

independent variables used in the regression models are analysed (Table 2), it can be observed that Agric and Spectro have a slightly higher number of authors than the other disciplines, while Telecom shows the lowest RCR values.

Table 1. Dependent and independent variables used in Logistic Regression models

\begin{tabular}{|c|c|c|c|c|c|c|c|c|c|c|}
\hline & \multicolumn{2}{|c|}{ Agric } & \multicolumn{2}{|c|}{ Biodiv } & \multicolumn{2}{|c|}{ Spectro } & \multicolumn{2}{|c|}{ Telecom } & \multicolumn{2}{|c|}{ Total } \\
\hline Without FA & 412 & $25.9 \%$ & 154 & $12.7 \%$ & 362 & $24.1 \%$ & 438 & $17.3 \%$ & 1366 & $20.0 \%$ \\
\hline Only National FA & 787 & $49 \cdot 4 \%$ & 489 & $40.4 \%$ & 607 & $40.5 \%$ & 1102 & $43.5 \%$ & 2985 & $43.7 \%$ \\
\hline International FA & 393 & $24.7 \%$ & 566 & $46.8 \%$ & 530 & $35 \cdot 4 \%$ & 995 & $39.3 \%$ & 2484 & $36.3 \%$ \\
\hline Total Articles & 1592 & $100.0 \%$ & 1209 & $100.0 \%$ & 1499 & $100.0 \%$ & 2535 & $100.0 \%$ & 6835 & $100.0 \%$ \\
\hline Only Other Foreign FA & 286 & $72.8 \%$ & 328 & $58.0 \%$ & 329 & $62.1 \%$ & 351 & $35 \cdot 3 \%$ & 1294 & $52.1 \%$ \\
\hline EU FA & 107 & $27.2 \%$ & 238 & $42.0 \%$ & 201 & $37.9 \%$ & 644 & $64.7 \%$ & 1190 & $47.9 \%$ \\
\hline \multirow[t]{2}{*}{ Total International FA } & 393 & $100.0 \%$ & 566 & $100.0 \%$ & 530 & $100.0 \%$ & 995 & $100.0 \%$ & 2484 & $100.0 \%$ \\
\hline & \multicolumn{2}{|c|}{ Agric } & \multicolumn{2}{|c|}{ Biodiv } & \multicolumn{2}{|c|}{ Spectro } & \multicolumn{2}{|c|}{ Telecom } & \multicolumn{2}{|c|}{ Total } \\
\hline Without Collaboration & 367 & $23.1 \%$ & 193 & $16.0 \%$ & 362 & $24.1 \%$ & 899 & $35.5 \%$ & 1821 & $26.6 \%$ \\
\hline Only National Collaboration & 573 & $36.0 \%$ & 296 & $24.5 \%$ & 364 & $24.3 \%$ & 498 & $19.6 \%$ & 1731 & $25 \cdot 3 \%$ \\
\hline International Collaboration & 652 & $41.0 \%$ & 720 & $59.6 \%$ & 773 & $51.6 \%$ & 1138 & $44.9 \%$ & 3283 & $48.0 \%$ \\
\hline Total Articles & 1592 & $100.0 \%$ & 1209 & $100.0 \%$ & 1499 & $100.0 \%$ & 2535 & $100.0 \%$ & 6835 & $100.0 \%$ \\
\hline
\end{tabular}

Table 2. Continuous independent variables used in Logistic Regression models

\begin{tabular}{llccccc}
\hline & & Agric & Biodiv & Spectro & Telecom & Total \\
\hline Author & Mean & 5.62 & 5.76 & 13.13 & 4.33 & 6.82 \\
& Median & 5 & 4 & 5 & 4 & 4 \\
& Percentile 75 & 7 & 6 & 7 & 5 & 6 \\
\hline RCR & Mean & 1.09 & 1.28 & 1.21 & 1.03 & 1.13 \\
& Median & 0.80 & 0.77 & 0.76 & 0.54 & 0.68 \\
& Percentile 75 & 1.50 & 1.43 & 1.50 & 1.21 & 1.39 \\
\hline
\end{tabular}

\section{Logistic Regression analyses}

In order to reveal the characteristics of research supported by international funds, logistic regression models are built with the dependent variable international FA. This variable accounts for $36.3 \%$ of the total analysed articles (Table 1 ) and its best explanatory variables are international collaboration, disciplines, RCR and number of authors (Table 3 ). Moreover, interactions between disciplines and international collaboration are also significant. Conversely, neither the interactions between disciplines and RCR are significant, nor between RCR and international collaboration. Therefore, to gain degrees of freedom they are excluded from the analysis. The final model has a Nagelkerke's $R^{2}$ of 0.287 , with an increase of $9.2 \%$ of correctly classified cases (Appendix Table 6) with respect to the null model. As shown in Table 3 , international FA is strongly linked to the existence of international collaboration $(\mathrm{OR}=7.6, \mathrm{p}<0.001)$ and to research in Biodiv and Telecom. Besides, research with international support has a higher $\mathrm{RCR}(\mathrm{OR}=1.1, \mathrm{p}<0.001)$ and a slightly higher number of authors. 
This is a postprint version of:

Morillo, F. (2019). Collaboration and impact of research in different disciplines with international funding (from the EU and other foreign sources). Scientometrics, 120(2), 807-823.

The final publication is available at Springer via https://doi.org/10.1007/s11192-019-03150-8

Table 3. Logistic Regression for International FA

\begin{tabular}{lllll}
\hline & B & S.E. & Sig. & OR \\
\hline Discipline * & & & 0.000 & \\
$\quad$ Biodiv & 0.465 & 0.169 & 0.006 & 1.592 \\
$\quad$ Spectro & 0.219 & 0.158 & 0.166 & 1.245 \\
$\quad$ Telecom & 0.988 & 0.127 & 0.000 & 2.685 \\
International Coll & 2.028 & 0.135 & 0.000 & 7.596 \\
Author & 0.009 & 0.003 & 0.003 & 1.009 \\
RCR & 0.092 & 0.019 & 0.000 & 1.096 \\
Discipline * International Coll & & & 0.000 & \\
$\quad$ Biodiv by International Coll & 0.459 & 0.203 & 0.024 & 1.583 \\
$\quad$ Spectro by International Coll & 0.149 & 0.192 & 0.438 & 1.161 \\
$\quad$ Telecom by International Coll & -0.401 & 0.161 & 0.013 & 0.669 \\
Constant & -2.355 & 0.112 & 0.000 & 0.095 \\
\hline * Reference discipline: Agric. & & & & \\
OR = Odds ratio = Exp(B) & & & &
\end{tabular}

Furthermore, Table 3 shows the strong interactions between Biodiv and international collaboration, since the latter increases even more the probabilities of obtaining international funds in this discipline. Conversely, in the case of Telecom and in comparison with the rest of the disciplines, the probabilities of obtaining this type of funds are not so enhanced by international cooperation. Figure 1 illustrates these interactions. On the one hand, Biodiv moves from the second to the first position, in terms of the mean predicted probability for international FA, due to the presence of international cooperation. On the other hand, Telecom exhibits the opposite trend, moving from the first to the second position.

Figure 1. Mean Predicted probability for International FA by International Collaboration and discipline

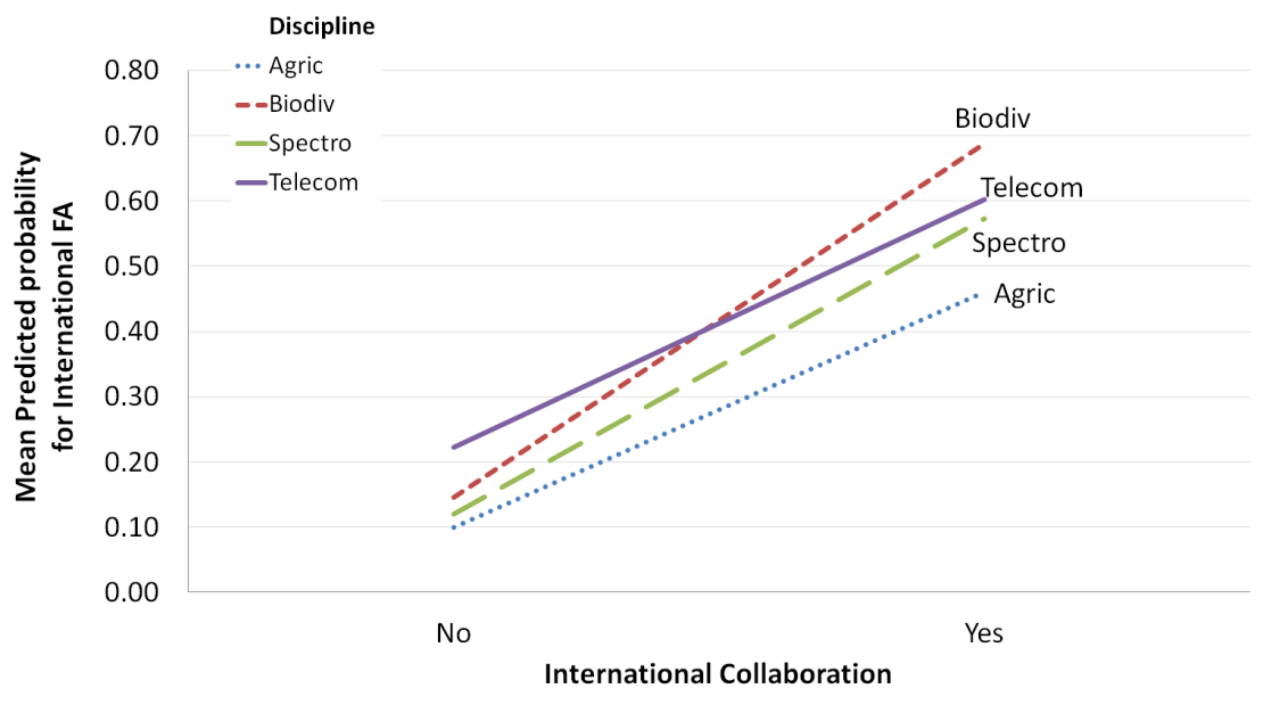

If the details of the internationally funded research are examined, it is possible to identify which publications are sponsored by the EU. In this case, the research supported by EU funds is compared 
This is a postprint version of:

Morillo, F. (2019). Collaboration and impact of research in different disciplines with international funding (from the EU and other foreign sources). Scientometrics, 120(2), 807-823.

The final publication is available at Springer via

with the one sponsored by only other foreign funds. Logistic regression models are built with the dependent variable EU FA, representing $47.9 \%$ of the total analysed articles (Table 1 ), and both the main effects and the interactions between variables are obtained. The variables that best explain the presence of this type of funding are, again, disciplines and RCR and, as for the presence of international collaboration, this has the opposite effect, since the probability of EU FA decreases when there is international collaboration. Additionally, interactions between disciplines and international collaboration also occur in this same direction (Table 4 ). However, neither the interactions between disciplines and RCR are significant, nor between RCR and international collaboration. The final model has a Nagelkerke's $R^{2}$ of 0.201 , with an increase of $14.7 \%$ of correctly classified cases (Appendix Table 7) with respect to the null model. In this case, the presence of EU FA is strongly linked to research in certain disciplines, such as Telecom, with an OR=9.7 ( $p<0.001)$ when there is no international collaboration. Nevertheless, despite the lower collaboration observed for EU FA, the RCR values are significantly higher in articles sponsored by this type of funds (OR=1.1, $p<0.001)$.

Table 4. Logistic Regression for EU FA

\begin{tabular}{lcccc}
\hline & B & S.E. & Sig. & OR \\
\hline Discipline * & & & 0.000 & \\
$\quad$ Biodiv & 1.473 & 0.339 & 0.000 & 4.363 \\
$\quad$ Spectro & 1.402 & 0.318 & 0.000 & 4.062 \\
$\quad$ Telecom & 2.276 & 0.267 & 0.000 & 9.738 \\
International Coll & -0.552 & 0.255 & 0.031 & 0.576 \\
Author & 0.003 & 0.001 & 0.054 & 1.003 \\
RCR & 0.116 & 0.025 & 0.000 & 1.123 \\
Discipline * International Coll & & & 0.008 & \\
$\quad$ Biodiv by International Coll & -0.893 & 0.377 & 0.018 & 0.410 \\
$\quad$ Spectro by International Coll & -1.134 & 0.362 & 0.002 & 0.322 \\
$\quad$ Telecom by International Coll & -0.901 & 0.308 & 0.003 & 0.406 \\
Constant & -0.744 & 0.219 & 0.001 & 0.475 \\
\hline * Reference discipline: Agric. & & & & \\
$\quad$ OR = Odds ratio = Exp(B) & & & &
\end{tabular}

In fact, all the disciplines show a greater probability of EU FA when there is no international cooperation, contrary to what happens in the model that has international FA as the dependent variable. Figure 2 illustrates these interactions, and it can be observed that for Telecom, Biodiv and Spectro, the existence of international collaboration in publications decreases the mean predicted probability for EU FA to a greater extent than for Agric. 
This is a postprint version of:

Morillo, F. (2019). Collaboration and impact of research in different disciplines with international funding (from the EU and other foreign sources). Scientometrics, 120(2), 807-823.

The final publication is available at Springer via

Figure 2. Mean Predicted probability for EU FA by International Collaboration and discipline

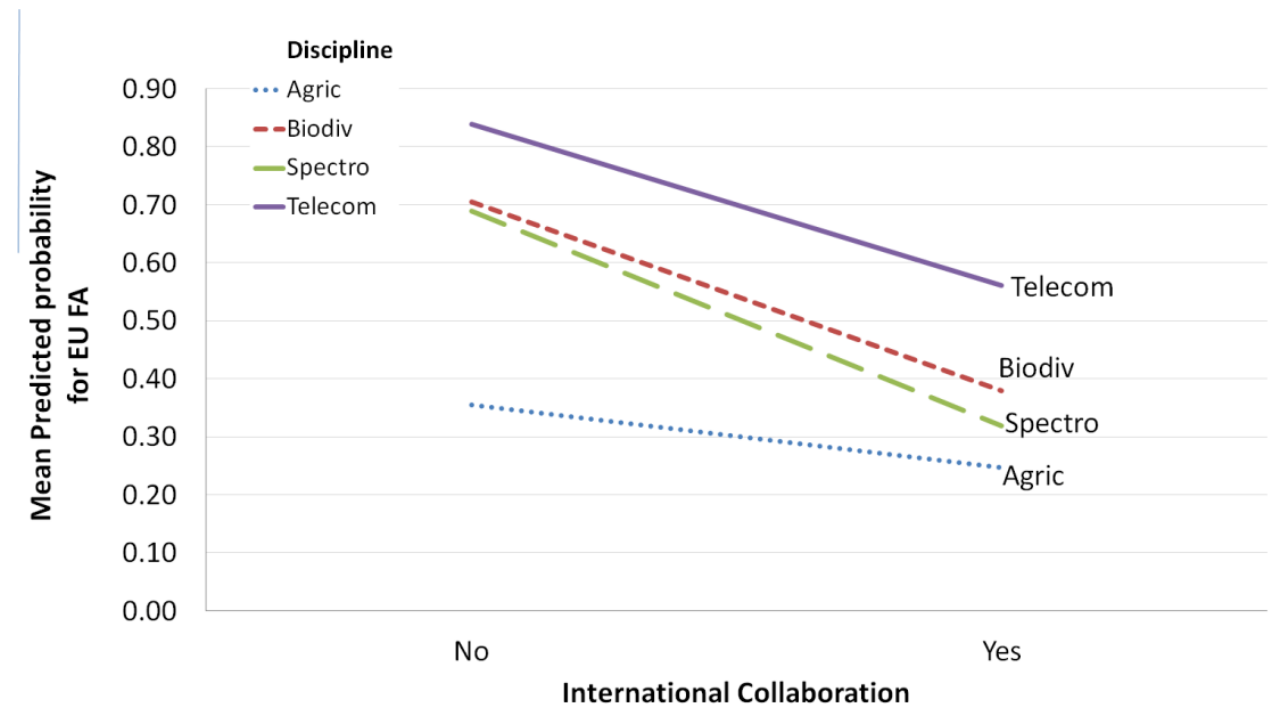

\section{Discussion}

Scientific research demands ever-increasing collaboration rates to carry out its goals. In turn, science managers are interested in promoting such collaboration, mainly if it is international in scope and allows access to international funds (either from foreign countries or from the EU as a whole). For this reason, this work focuses on analysing the possible interaction between international funding, collaboration and research impact. It is considered that this information will be of interest to both managers and researchers, who are increasingly encouraged to cooperate and publish beyond national borders. The results offered in the present study corroborate the first hypothesis of higher percentages of international funding in cases with a clear international orientation, as reflected through collaboration. This orientation can be seen in Biodiv, which stands out for its large international collaboration and its high proportion of international funds. The latter account for more than $50 \%$ of the total number of articles with FA, which represent more than $87 \%$ of the publications of this discipline, being the first by percentage of FA (Table 1 ). This weight of international funding is especially remarkable since domestic funding dominates on average (as also noted by other authors such as Álvarez-Bornstein et al. 2018 or Huang and Huang 2018). In addition, Biodiv is also the discipline with the highest proportion of collaborative publications (84\%). All this may explain why this discipline discloses such strong interactions between international funding and international cooperation, since the latter further increases the probability of obtaining this type of sponsorship (Table 3 and Figure 1 ). On the other hand, Agric is the discipline with the clearest national orientation, as can be inferred from its meaningful proportion of articles with only national collaboration, which could explain its high proportion of only national funds (Table 1 and Appendix Table 5). 
This is a postprint version of:

Morillo, F. (2019). Collaboration and impact of research in different disciplines with international funding (from the EU and other foreign sources). Scientometrics, 120(2), 807-823.

The final publication is available at Springer via

When percentages of collaboration are analysed, the second hypothesis is confirmed, because there is greater cooperation in articles with some international funding (Appendix Table 5 ). This connection becomes even more apparent when the type of collaboration is international, as shown in the logistic regression analysis of Table 3 . This is in line with what is pointed out by authors such as Álvarez-Bornstein et al. (2018). Besides, there are some differences between disciplines. For instance, when international collaboration is present, research in Telecom does not reveal the expected trend in its international funding probabilities, compared with the other disciplines (Figure 1). This is quite surprising, since this is the second discipline by proportion of international FA, which is closely linked to international cooperation. However, this is also an unexpected behaviour for an applied discipline, especially considering that it has the lowest collaboration percentage (less than $65 \%$ ). In fact, it gives the impression that this discipline is formed by two research scopes: a domestic and an international one. The first scope would be supported by only national sources, showing little collaboration (only national FA has less than $50 \%$ of articles in collaboration as can be seen in Appendix Table 5 ). On the contrary, the second scope would obtain international funding, mainly from EU funds (65\%), with higher cooperation than the first one (Table 1 ).

Notwithstanding, Table 4 shows the existence of lower international collaboration rates for research with EU FA than for only other foreign funds, although with some differences by discipline. For example, international cooperation decreases the probability of obtaining EU FA to a lesser extent for Agric, perhaps due to its lower proportion of this type of collaboration and support. With regard to significantly higher collaborative values for research funded by only other foreign sources, these could be due to foreign coauthors with funding from their respective countries. Conversely, those cases without collaboration would be generally due to coauthors with grants from foreign countries not included as affiliations or to foreign funders with an address in Spain. Considering the research funded by the EU, its lower proportion of international collaboration could be partly explained by research contracts such as Marie Curie, or by the findings of Defazio et al. (2009). These authors point out that relationships formed to attract funding, without the existence of previous joint publications, might take longer to establish effective collaborations. Furthermore, something that should also be taken into account is the relevant proportion of agreements between countries or EU projects in which the Spanish group publishes the results independently, so collaboration in these cases may not be detected through coauthorship. As several authors have already pointed out, cooperation can take place in different ways and coauthorship is only one of them (e.g. Ebadi \& Schiffauerova 2013). Indeed, evidence has been found that EU funding implies a collaboration that goes beyond what can be measured through the publications' addresses (Lewison 1994), which is not the case with articles with FA from only other type of international support. This fact, apart from the domestic dimension of Telecom, could explain why, being the discipline with the lowest

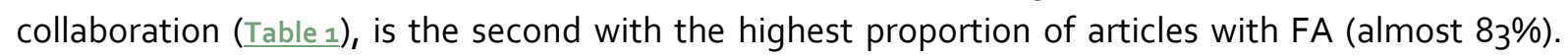
Moreover, in general, there is also less collaboration in publications with only national funding, even lower than that in articles without FA. Although this result was not foreseen in the objectives, it seems quite logical, since the publications with only national funds do not require interactions between organisations, while the publications without acknowledgements may have received some kind of economic support not explicitly mentioned that influences the cooperation. However, the 
This is a postprint version of:

Morillo, F. (2019). Collaboration and impact of research in different disciplines with international funding (from the EU and other foreign sources). Scientometrics, 120(2), 807-823.

The final publication is available at Springer via

lower collaboration reflected in publications with only national funding, and the one seen for the research supported by EU funds, influences the average cooperation of publications with FA, which is slightly lower than that of publications without FA (Appendix Table 5 ). This outcome contrasts with the findings of previous works, in which there is more collaboration in papers with some sponsorship (Zhao 2010). In any case, it must be taken into account that this collaboration and funding is the one shown in publications.

With respect to the last hypothesis of higher citation rates for internationally funded research, this is confirmed through the logistic regression analysis (Table 3 ). Besides this higher RCR can be indirectly linked to a greater international collaboration, although there are neither interactions between them nor significant differences between research fields. These results are consistent with what was observed in previous studies, that both international collaboration and/or the variety of funding sources are related to greater citation rates (Gök et al. 2016; Morillo 2016). Nevertheless, other input variables must also be taken into account. For example, Lewison and Dawson (1998) observe that the average impact of a group of articles increases with the number of authors, the type of research (more basic than clinical) and the number and identity of the funders. In this work, the number of authors is slightly higher when there is international FA, which is indirectly connected with RCR, although the type of research does not seem to have an influence on results. On the other hand, the impact measured through RCR is higher for EU FA, contrary to what is predicted in the third hypothesis (Table 4), although in line with previous works (Gök et al. 2016). That is to say, research with EU FA receives more citations than research sponsored by only other foreign sources, possibly due to the close collaboration existing in projects with European support, although not reflected through publications.

\section{Limitations and challenges}

The main limitation of this study is given by the data source used (WoS) and by the analysed set (articles of the years 2010-2014 with Spanish addresses). Besides, WoS has a very broad coverage, but it is still incomplete. Furthermore, not all research fields include the same proportion of FA, perhaps due to less dependence on external funding sources (Grassano et al. 2017). On the other hand, when trying to quantify the presence of different types of funders, it should be noted that some might be overrepresented, while others are not at all mentioned. The first case can be found in works signed by authors who wish to improve their professional status, while the second is usually explained by the laxity of authors or the desire of some organisations to maintain their anonymity (Grassano et al. 2017; Morillo and Álvarez-Bornstein 2018; Rigby 2011; Wang and Shapira 2011).

Moreover, the difficulty of correctly identifying specific agencies or programmes must be considered, as is the case of those funds coming from the EU. Therefore, it is necessary to perform a standardisation procedure (Begum and Lewison 2017; Morillo and Álvarez-Bornstein 2018). This is particularly important in this study, given that it has been decided to analyse ESIF together with national funding. The reason is that the proposals management is carried out in a decentralised manner by the different EU countries, which follows a different competitive process from that of the Framework Programme. Although other authors such as Gök et al. (2016) or Wang and Shapira 
This is a postprint version of:

Morillo, F. (2019). Collaboration and impact of research in different disciplines with international funding (from the EU and other foreign sources). Scientometrics, 120(2), 807-823.

The final publication is available at Springer via

(2011) treat all the EU sponsorship as a whole, in the present study the objective is to evaluate the effect of true international support compared with the absence of it. Indeed, Gök et al. (2016) conclude that there is some kind of hierarchy with regard to the impact associated with funding sources, because, in general, international funders like the EU receive more citations that national ones.

Finally, a potential drawback in the analysis of funding with respect to collaboration is that this work does not conduct an exhaustive study on the type of support received by each particular author, since it is often not feasible to establish this connection (Grassano et al. 2017). Nonetheless, for only other foreign funds, as mentioned above, foreign coauthors would be the main recipients. In these cases, although some authors did not receive direct financial support, it is assumed that the final research result would also benefit from the indirect funding obtained through collaboration. In fact, Rigby (2011) considers that a publication cannot be attributed to a single grant. This author does not believe that a funding grant is just an input for a publication, but for a complete process that can produce different results depending on the various research features. In this line, in a previous work, Lewison (1994) already raised the need to resort to additional data sources, which could be the internal acknowledgements, as suggested by Grassano et al. (2017), reviewing, for instance, the addresses of the authors (Begum and Lewison 2017).

\section{Conclusions}

This paper offers a joint analysis, showing the relationship between collaboration, research impact and international funding (from the EU and other foreign sources). Four disciplines with dissimilar behaviour are analysed and findings demonstrate that, for all of them, the research with some international sponsorship is also the one with the greatest collaboration, especially international, which is coherent with the hypothesis raised. However, there are also some differences between disciplines. For instance, Biodiv experiments a strong increase in the probability of international funding when there is international collaboration, while Telecom does not show the same trend, since there is a smaller increase than expected. Besides, as explained in the Discussion section and also anticipated in this hypothesis, less cooperation is found in articles with EU funding. On the other hand, an unforeseen result shows that research with only national sponsors has even less collaboration than research without FA, which influences the slightly lower average cooperation of FA publications and implies that the explicit sponsorship recognition is not necessarily linked to collaboration. Regarding the last hypothesis, this is also fulfilled in all disciplines, since there is a greater impact in publications with international financing. Nevertheless, there are unexpected findings due to the origin of international sources. The research funded with EU support receives higher citation rates, although it has lower collaboration than that sponsored by only other foreign sources, which could possibly be explained by connections not shown through publications. Finally, a specific contribution of this work is the analysis of national funds together with ESIF, managed directly by each EU country. In this way, the results of collaboration and impact take into account the different competitive processes followed to obtain the various types of funds. 
This is a postprint version of:

Morillo, F. (2019). Collaboration and impact of research in different disciplines with international funding (from the EU and other foreign sources). Scientometrics, 120(2), 807-823.

The final publication is available at Springer via https://doi.org/10.1007/s11192-019-03150-8

The findings of this work show how the different characteristics of disciplines and funding types require a detailed analysis in order to improve the available data. Although the information offered in this paper has its limitations, it can serve the main funding agencies to analyse their context. This context can help them to study which programmes or interactions with other sources of funding can be more useful to achieve specific research goals (Grassano et al. 2017). This will not only increase the quantity but also the quality of the performed research. Moreover, it could provide indications for a better distribution of funding that would increase efficiency in terms of results and impact, as some authors suggest (e.g. Braun 1998; Mongeon et al. 2016; Wang et al. 2018; Wu et al. 2018). For all these reasons, future research will still have to consider supplementary variables to offer a more complete frame of reference for both evaluators and researchers.

\section{Acknowledgements}

This work is supported by the Spanish Ministry of Economy and Competitiveness (Grant CSO2014-57826-P). Valuable assistance is also acknowledged from José Manuel Rojo (Statistical Analysis Unit, (CHS-CSIC) and useful comments from two anonymous reviewers.

\section{Appendix}

See Table 5 , Table 6 and Table 7.

Table 5. FA types vs Collaboration types by discipline

\begin{tabular}{|c|c|c|c|c|c|c|c|c|c|c|}
\hline \multirow[b]{2}{*}{ Without FA } & \multicolumn{2}{|c|}{ Agric } & \multicolumn{2}{|c|}{ Biodiv } & \multicolumn{2}{|c|}{ Spectro } & \multicolumn{2}{|c|}{ Telecom } & \multicolumn{2}{|c|}{ Total } \\
\hline & 412 & $100.0 \%$ & 154 & $100.0 \%$ & 362 & $100.0 \%$ & 438 & $100.0 \%$ & 1366 & $100.0 \%$ \\
\hline Without Collaboration & 96 & $23.3 \%$ & 38 & $24.7 \%$ & 80 & $22.1 \%$ & 143 & $32.6 \%$ & 357 & $26.1 \%$ \\
\hline Only National Collaboration & 138 & $33 \cdot 5 \%$ & 44 & $28.6 \%$ & 92 & $25.4 \%$ & 79 & $18.0 \%$ & 353 & $25.8 \%$ \\
\hline International Collaboration & 178 & $43.2 \%$ & 72 & $46.8 \%$ & 190 & $52.5 \%$ & 216 & $49 \cdot 3 \%$ & 656 & $48.0 \%$ \\
\hline Only National FA & 787 & $100.0 \%$ & 489 & $100.0 \%$ & 607 & $100.0 \%$ & 1102 & $100.0 \%$ & 2985 & $100.0 \%$ \\
\hline Without Collaboration & 233 & $29.6 \%$ & 134 & $27.4 \%$ & 249 & $41.0 \%$ & 552 & $50.1 \%$ & 1168 & $39.1 \%$ \\
\hline Only National Collaboration & 380 & $48.3 \%$ & 202 & $41.3 \%$ & 218 & $35 \cdot 9 \%$ & 313 & $28.4 \%$ & 1113 & $37.3 \%$ \\
\hline International Collaboration & 174 & $22.1 \%$ & 153 & $31.3 \%$ & 140 & $23.1 \%$ & 237 & $21.5 \%$ & 704 & $23.6 \%$ \\
\hline International FA & 393 & $100.0 \%$ & 566 & $100.0 \%$ & 530 & $100.0 \%$ & 995 & $100.0 \%$ & 2484 & $100.0 \%$ \\
\hline Without Collaboration & 38 & $9.7 \%$ & 21 & $3.7 \%$ & 33 & $6.2 \%$ & 204 & $20.5 \%$ & 296 & $11.9 \%$ \\
\hline Only National Collaboration & 55 & $14.0 \%$ & 50 & $8.8 \%$ & 54 & $10.2 \%$ & 106 & $10.7 \%$ & 265 & $10.7 \%$ \\
\hline International Collaboration & 300 & $76.3 \%$ & 495 & $87.5 \%$ & 443 & $83.6 \%$ & 685 & $68.8 \%$ & 1923 & $77.4 \%$ \\
\hline Total & 1592 & & 1209 & & 1499 & & 2535 & & 6835 & \\
\hline
\end{tabular}

Table 6. Classification Table ${ }^{a}$ of the model for International FA

\begin{tabular}{lrrr}
\hline Observed & \multicolumn{3}{c}{ Predicted } \\
International FA & No & Yes & $\begin{array}{c}\text { Percentage } \\
\text { Correct }\end{array}$ \\
\hline No & 3320 & 1031 & 76.3 \\
Yes & 826 & 1658 & 66.7 \\
\hline Overall Percentage & \multicolumn{4}{c}{} \\
\hline a. The cut value is .500 & \multicolumn{4}{c}{} \\
\hline
\end{tabular}


This is a postprint version of:

Morillo, F. (2019). Collaboration and impact of research in different disciplines with international funding (from the EU and other foreign sources). Scientometrics, 120(2), 807-823.

The final publication is available at Springer via https://doi.org/10.1007/s11192-019-03150-8

Table 7. Classification Table ${ }^{\mathrm{a}}$ of the model for EU FA

\begin{tabular}{cccc}
\hline Observed & \multicolumn{3}{c}{ Predicted } \\
EU FA & No & Yes & $\begin{array}{c}\text { Percentage } \\
\text { Correct }\end{array}$ \\
\hline No & 877 & 417 & 67.8 \\
Yes & 407 & 783 & 65.8 \\
\hline Overall Percentage & \multicolumn{4}{c}{} \\
\hline a. The cut value is .500 & \multicolumn{4}{c}{}
\end{tabular}

\section{References}

Álvarez-Bornstein, B., Morillo, F., \& Bordons, M. (2017). Funding acknowledgments in the Web of Science: completeness and accuracy of collected data. Scientometrics, 112(3), 1793-1812.

doi:10.1007/s11192-017-2453-4

Álvarez-Bornstein, B., Bordons, M., Costas, R., \& Calero-Medina, C. (2018). Studying the research funding structure of countries through the analysis of funding acknowledgments. In 23rd International Conference on Science and Technology Indicators (STI 2018), September 12-14, 2018, Leiden, The Netherlands. Centre for Science and Technology Studies (CWTS). Retrieved from https://openaccess.leidenuniv.nl/bitstream/handle/1887/65363/STI2018_paper_195.pdf? sequence=1. Accessed January 29, 2019.

Begum, M., \& Lewison, G. (2017). Web of Science Research Funding Information: Methodology for its use in Analysis and Evaluation. Journal of Scientometric Research, 6(2): 65-73. doi:10.5530/jscires.6.2.12

Braun, D. (1998). The role of funding agencies in the cognitive development of science. Research Policy, 27(8), 807-821. doi:10.1016/S0048-7333(98)00092-4

Clark, B. Y., \& Llorens, J. J. (2012). Investments in scientific research: Examining the funding threshold effects on scientific collaboration and variation by academic discipline. Policy Studies Journal, 40(4), 698-729. doi:10.1111/j.1541-0072.2012.00470.x

Costas, R., \& van Leeuwen, T. N. (2012). Approaching the "reward triangle": General analysis of the presence of funding acknowledgments and "peer interactive communication" in scientific publications. Journal of the American Society for Information Science and Technology, 63(8), 1647-1661. doi:10.1002/asi.22692

Cummings, J. N., \& Kiesler, S. (2005). Collaborative research across disciplinary and organizational boundaries. Social studies of science, 35(5), 703-722. doi:10.1177/0306312705055535

Defazio, D., Lockett, A., \& Wright, M. (2009). Funding incentives, collaborative dynamics and scientific productivity: Evidence from the EU framework program. Research Policy, 38(2), 293-305.

doi:10.1016/j.respol.2008.11.008

Díaz-Faes, A. A., \& Bordons, M. (2014). Acknowledgements in scientific publications: presence in Spanish science and text patterns across disciplines. Journal of the Association for Information Science and Technology, 65(9), 1834-1849. doi:10.1002/asi.23081

Ebadi, A., \& Schiffauerova, A. (2013). Impact of funding on scientific output and collaboration: A survey of literature. Journal of Information \& Knowledge Management, 12(04), 1350037. doi:10.1142/S0219649213500378

Ebadi, A., \& Schiffauerova, A. (2015). How to Receive More Funding for Your Research? Get Connected to the Right People! PLOS ONE, 10(7): e0133061. doi:10.1371/journal.pone.0133061

Ebadi, A., \& Schiffauerova, A. (2016). How to boost scientific production? A statistical analysis of research funding and other influencing factors. Scientometrics, 106(3), 1093-1116. doi:10.1007/s11192-015-1825-X 
This is a postprint version of:

Morillo, F. (2019). Collaboration and impact of research in different disciplines with international funding (from the EU and other foreign sources). Scientometrics, 120(2), 807-823.

The final publication is available at Springer via https://doi.org/10.1007/s11192-019-03150-8

Gök, A., Rigby, J., \& Shapira, P. (2016). The impact of research funding on scientific outputs: Evidence from six smaller E uropean countries. Journal of the Association for Information Science and Technology, 67(3), 715-730. doi:10.1002/asi.23406

Grassano, N., Rotolo, D., Hutton, J., Lang, F., \& Hopkins, M. M. (2017). Funding data from publication acknowledgments: Coverage, uses, and limitations. Journal of the Association for Information Science and Technology, 68(4), 999-1017. doi:10.1002/asi.23737

Huang, M. H., \& Huang, M. J. (2018). An analysis of global research funding from subject field and funding agencies perspectives in the $G 9$ countries. Scientometrics, 115(2), 833-847. doi:10.1007/s11192-018-2677-y

Jaffe, A. B. (2002). Building programme evaluation into the design of public research-support programmes. Oxford Review of Economic Policy, 18(1), 22-34. doi:10.1093/oxrep/18.1.22

Langfeldt, L., Bloch, C. W., \& Sivertsen, G. (2015). Options and limitations in measuring the impact of research grants-evidence from Denmark and Norway. Research Evaluation, 24(3), 256-270.

doi:10.1093/reseval//rvvo12

Laudel, G. (2002). What do we measure by co-authorships? Research Evaluation, 11(1), 3-15. doi:10.3152/147154402781776961

Lewison, G. (1994). Publications from the European Community's Biotechnology Action Programme (BAP): multinationality, acknowledgement of support, and citations. Scientometrics, 31(2), 125-142.

doi:10.1007/BF02018556

Lewison, G., \& Dawson, G. (1998). The effect of funding on the outputs of biomedical research. Scientometrics, 41(1-2), 17-27. doi:10.1007/BF02457963

MacLean, M., Anderson, J., \& Martin, B. R. (1998a). Identifying research priorities in public sector funding agencies: mapping science outputs on to user needs. Technology Analysis \& Strategic Management, 10(2), 139-155. doi:10.1080/09537329808524308

MacLean, M., Davies, C., Lewison, G., \& Anderson, J. (1998b). Evaluating the research activity and impact of funding agencies. Research Evaluation, 7(1), 7-16. doi:10.1093/rev/7.1.7

Mongeon, P., Brodeur, C., Beaudry, C., \& Larivière, V. (2016). Concentration of research funding leads to decreasing marginal returns. Research Evaluation, 25(4), 396-404. doi:10.1093/reseval/rvwoo7

Morillo, F. (2016). Public-private interactions reflected through the funding acknowledgements. Scientometrics, 108(3), 1193-1204. doi:10.1007/s11192-016-2032-0

Morillo, F., \& Álvarez-Bornstein, B. (2018). How to automatically identify major research sponsors selecting keywords from the WoS Funding Agency field. Scientometrics, 117(3), 1755-1770. doi:10.1007/s11192-018-2947-8

Nomaler, Ö., Frenken, K., \& Heimeriks, G. (2013). Do more distant collaborations have more citation impact?. Journal of Informetrics, 7(4), 966-971. doi:10.1016/j.joi.2013.10.001

Rigby, J. (2011). Systematic grant and funding body acknowledgement data for publications: New dimensions and new controversies for research policy and evaluation. Research Evaluation, 20(5), 365-375. doi:10.3152/095820211X13164389670392

Wang, J., Lee, Y. N., \& Walsh, J. P. (2018). Funding model and creativity in science: Competitive versus block funding and status contingency effects. Research Policy, 47(6), 1070-1083. doi:10.1016/j.respol.2018.03.014

Wang, J., \& Shapira, P. (2011). Funding acknowledgement analysis: an enhanced tool to investigate research sponsorship impacts: the case of nanotechnology. Scientometrics, 87(3), 563-586.

doi:10.1007/s11192-011-0362-5

Wang, J., \& Shapira, P. (2015). Is There a Relationship between Research Sponsorship and Publication Impact? An Analysis of Funding Acknowledgments in Nanotechnology Papers. PLOS ONE, 10(2): e0117727.

doi:10.1371/journal.pone. 0117727 
This is a postprint version of:

Morillo, F. (2019). Collaboration and impact of research in different disciplines with international funding (from the EU and other foreign sources). Scientometrics, 120(2), 807-823.

The final publication is available at Springer via

Wu, D., Yuan, L., Li, R., \& Li, J. (2018). Decomposing inequality in research funding by university-institute sub-group: A three-stage nested Theil index. Journal of Informetrics, 12(4), 1312-1326. doi:10.1016/j.joi.2018.10.007

Yan, E., Wu, C., \& Song, M. (2018). The funding factor: a cross-disciplinary examination of the association between research funding and citation impact. Scientometrics, 115(1), 369-384.

doi:10.1007/s11192-017-2583-8

Zhao, D. (2010). Characteristics and impact of grant-funded research: a case study of the library and information science field. Scientometrics, 84(2), 293-306. doi:10.1007/s11192-010-0191-y 